\title{
ABSTRAK \\ Gambaran Pengetahuan Remaja Putri Tentang Pernikahan Dini \\ Di SMPN Anreapi Kec. Anreapi \\ Kab. Polewali Mandar
}

\author{
Rosdiana ${ }^{1}$, Indra, $S^{2}$, Harianti $^{3}$, Zalfawi Widya Putri ${ }^{4}$ \\ (vi+ 66 Halaman +9 Tabel + 7 Lampiran)
}

Latar belakang : Pernikahan dini menjadi salah satu persoalan yang terus dilakukan upaya untuk mengatasinya karena pernikahan dini menghasilkan banyak dampak negatif, tidak hanya bagi individu yang melakukan pernikahan dini tersebut, melainkan juga bagi negara karena dengan menikah dini, banyak anak-anak di Indonesia menjadi putus sekolah, akibatnya angka pengangguran di Indonesia menjadi meningkat dan kualitas SDM semakin rendah.

Kantor Urusan Agama Kecamatan Anreapi Kabupaten Polewali Mandar mengatakan bahwa terdapat 23 orang yang melalukan pernikahan dini pada tahun 2016 dan mengalami peningkatan pada tahun 2017 yaitu mencapai 37.

Tujuan :Untukmengetahui Gambaran Pengetahuan Remaja Putri Tentang Pernikahan Dini Di SMPN Anreapi Kec. Anreapi Kab. Polewali Mandar.

Metode penelitian :Jenis penelitian yang digunakan adalah metode penelitian deskriftif kuantitatifyaitu metode yang dilakukan dengan satu tujuan membuat gambaran atau deskripsi tentang suatu keadaan secara objektif dalam bentuk angka-angka mulai dari pengumpulan data serta penampilan dari hasilnya. Jumlah populasi dalam penelitian ini adalah 65 orang siswi putri SMPN Anreapi.Penelitian ini dilaksanakan pada bulan agustus 2018 dengan menggunakan tehnik accidental. Accidental sampling adalah pengambilan sampel yang dilakukan sesaat. Sehingga sampel diperoleh adalah yang ada atau tersedia pada waktu itu.

Hasil : Secara keseluruhan gambaran pengetahuan remaja putri tentang Pernikahan Dini, dimana hasil penelitian menunjukan bahwa dari 65 responden yang memperoleh kriteria baik sebanyak 4 responden atau $(6,2 \%)$, yang memperoleh kriteria cukup sebanyak 46 responden atau $(70,77 \%)$ dan yang memperoleh kriteria kurang sebanyak 15 responden atau $(23,1 \%)$.

Kesimpulan : Berdasarkan penelitian diperoleh hasil tentang tingkat pengetahuan remaja putri tentang pernikahan dini di SMPN Anreapi Kecamatan Anreapi Kabupaten Polewali Mandar Tahun 2018 berada pada kategori cukup.

Saran : Diharapkan remaja agar dapat terus meningkatkan wawasan dan pengetahuan mengenai hal yang berhubungan dengan pernikahan dini sehingga para remaja dapat meningkatkan pengetahuan. 
$\begin{array}{ll}\text { Kata kunci } & \text { : Pengetahuan, Remaja putri, Pernikahan Dini, } \\ \text { Kepustakaam } & : 14+1 \text { jurnal }+2 \text { internet (2009-2016) }\end{array}$

\title{
ABSTRACT \\ Overview of Young Women Knowledge About Early Marriage At SMPN Anreapi Kec. Anreapi Kab. Polewali Mandar
}

\author{
Rosdiana $^{1}$, Indra, $\mathrm{S}^{2}$, Harianti $^{3}$, Zalfawi Widya Putri ${ }^{4}$ \\ (vii +66 pages +9 tables +7 attachments $)$
}

Background: Early marriage is one of the issues that continue to be done to overcome it because early marriage produces many negative effects, not only for individuals who are engaged in early marriage, but also for the country because by early marriage, many children in Indonesia become severed school, as a result the unemployment rate in Indonesia is increasing and the quality of human resources is getting lower.

The Office of Religious Affairs in Kec. Anreapi Kab. Polewali Mandar said that there were 23 people who had early marriages in 2016 and had increased in 2017, reaching 37.

Purpose: To find out the description of knowledgeTeen girls about marriage at SMPN Anreapi Kec. Anreapi Kab. Polewali Mandar.

Method of research: The type of research used is a method of research and quantitative criteria that are carried out by means of aiming to make a description or a description of the existence of objects objectively in terms of data collection from data collection and performance of the results. The number of population in this study is 65 students from SMPN Anreapi. This research was conducted in August 2018 using accidental techniques. Accidental sampling is a momentary sampling. So that the samples obtained are those that are available or available at that time.

Results: Overall a description of the knowledge of young women about Early Marriage, where the results of the study showed that from 65 respondents who obtained good criteria as many as 4 respondents or (6.2\%), who obtained enough criteria as many as 46 respondents or $(70.77 \%)$ and who received less criteria as many as 15 respondents or $(23.1 \%)$.

Conclusion: Based on the research, it was found that the level of knowledge of young women about early marriage at SMPN Anreapi Kec. Anreapi Kab. Polewali Mandar, 2018 was in the sufficient category.

Suggestion: It is expected that adolescents can continue to increase their insight and knowledge regarding matters related to early marriage so that teenagers can increase their knowledge.

Keywords: Knowledge, Young Women, Early Marriage, Kepustakaam: $14+1$ journal +2 internet (2009-2016) 
PENDAHULUAN

\section{Latar Belakang}

Menurut WHO (World

Health Organization) remaja merupakan anak yang telah mencapai usia 10 sampai 18 tahun, sedangkan Diknas (Pendidikan Nasional) menganggap anak remaja bila sudah berusia 18 tahun, yang sesuai dengan saat lulus sekolah menengah dan dalam buku-buku pediatri, seseorang anak dikatakan remaja apabila seorang anak telah mencapai usia 10-18 tahun untuk anak perempuan dan 12 sampai 20 tahun untuk anak laki-laki (Mansur 2011).

Menurut The Health Resources and Services Administrations Guidelines Amerika Serikat, rentang usia remaja adalah 11-21 tahun (Kusmiran 2011).

Menurut BKKBN (Badan Koordinasi Keluarga Berencana Nasional) remaja berusia 10-24 tahun, sementara Departemen Kesehatan dalam program kerjanya menjelaskan bahwa remaja adalah usia 1019 tahun (Adjie, 2010).

Masa remaja berlangsung melalui 3 tahapan yaitu masa remaja awal (10-14 tahun), menengah (15-16 tahun), dan akhir (17-20 tahun).Masa remaja awal ditandai dengan peningkatan cepat pertumbuhan dan pematangan fisik.Masa remaja menengah ditandai dengan hampir lengkapnya pertumbuhan pubertas, timbulnya keterampilan-keterampilan berpikir yang baru, peningkatan pengenalan terhadap datangnya masa dewasa, dan keinginan untuk memapankan jarak emosional dan psikologis dengan orangtua.Masa remaja akhir ditandai dengan persiapan untuk peran sebagai orang dewasa, termasuk klarifi kasi tujuan pekerjaan dan internalisasi suatu sistem nilai pribadi (Dhamayanti, 2013).

Remaja merupakan masa trasisi atau peralihan dari masa kanak-kanak ke masa dewasa, yang diawali dengan pubertas.Pada masa ini terjadi berbagai perubahan, baik dari segi fisik, sosial, maupun emosional, yang di awali oleh datangnya haid (perempuan) dan mimpi basah pertama (laki-laki).Menentukan titik awal masa remaja tidak mudah. Remaja (adolensence) berasal dari bahasa latin yang berarti tumbuh kearah kematangan (Muss,1968). Kematangan ini bukan hanya dari segi fisik, tetapi juga sosial dan 
emosional (psikologis) (Irianti dkk, 2011).

Remaja memiliki sifat menantang sesuatu yang dianggap kaku dan kolot.Mereka menginginkan kebebasan, sehingga sering menimbulkan konflik di dalam diri mereka.Oleh karena itu, diperlukan pendekatan dalam memahami alam dan pikiran remaja. Penyampaian pesan kesehatan dan bimbingan remaja mencakup perkawinan yang sehat, keluarga yang sehat, sistem reproduksi dan masalahnya, sikap dan prilaku remaja yang sehat, keluarga yang sehat, sistem reproduksi dan masalahnya, sikap dan prilaku remaja yang positif dan sebagainya (Mubarak, 2011).

Perkawinan dibawah umur masih sering ditemukan di daerah pedesaan.Kebiasaan ini bermula dari adat-istiadat yang berlaku pada wilayah tersebut.Hal ini yang menjadi tolak ukurnya adalah kematangan fisik atau yang tidak berkaitan dengan hal-hal dengan calon pengantin. Sebaliknya, di daerah perkotaan, seiring dengan meningkatnya tarap pendidikan masyarakat dan semakin banyaknya anak perempuan yang bersekolah, kebutuhan mereka untuk menikah di usia muda juga menurun (Irianti dkk, 2011).

Di Indonesia, pada tahun 2012, angka perempuan menikah usia 10-14 sebesar 4,2 persen, sementara perempuan menikah usia 15-19 tahun sebesar 41,8 persen (survei BKKBN dalam Desiyanti, 2015). Menurut data Survei Sosial dan Ekonomi Nasional (Susenas) yang dilakukan oleh Badan Pusat Statistik (BPS) pada tahun 2012, menunjukkan bahwa diantara perempuan pernah kawin usia 20-24 tahun 25 persen menikah sebelum usia 18 tahun. Artinya, lebih dari seperenam anak perempuan menikah sebelum mencapai usia dewasa atau sekitar $\quad 340.000 \quad$ anak perempuan setiap tahunnya. Prevalensi perkawinan usia anak di Indonesia tidak hanya tetap tinggi tetapi prevalensi tersebut juga telah kembali meningkat.

Pada tahun 2013 terjadi peningkatan rasio pernikahan muda pada daerah perkotaan dibandingkan dengan daerah pedesaan. Adapun jumlah rasio kenaikan tersebut pada daerah perkotaan pada tahun 2012 adalah 26 dari 1.000 perkawinan, rasio itu naik pada tahun 2013 menjadi 32 per 1.000 pernikahan. Sedangkan pada daerah pedesaan yang 
menurun dari 72 per 1000 pernikahan menjadi 67 per 1000 pernikahan pada tahun 2013 (Eko, 2013; dalam Desiyanti 2015).

Dari berbagai sumber media online dan laporan BPS (tahun tidak dicantumkan), beberapa provinsi di Indonesia masih memiliki angka prenikahan dini yang relatif tinggi. Di Yogyakarta dan DKI Jakarta memiliki angka 13,3 persen dan 13,7 persen. Kepulauan Riau dan Aceh tahun 2015 memiliki angka kejadian sebesar 11,7 persen dan 12,4 persen. Sulawesi Barat menduduki peringkat

\section{METODE PENELITIAN}

\section{Desain Penelitian}

Jenis penelitian yang
digunakan adalah metode
penelitian deskriftif
kuantitatif yaitu metode yang
dilakukan dengan satu tujuan
membuat gambaran atau
deskripsi tentang suatu
keadaan secara objektif
dalam bentuk angka-angka
mulai dari pengumpulan data
serta penampilan dari
hasilnya (Arikunto, 2010)
Dengan tujuan untuk
mengetahui gambaran
pengetahuan remaja putri
tentang pernikahan dini
dengan alat bantu kuesioner.

\section{Populasi dan Sampel}

pertama dengan rata-rata 36,2persen untuk perkawinan anak dan remaja, disusul dengan Kalimantan Tengah dan Sulawesi Tengah. Sedangkan di Indramayu pada tahun 2016 dispensasi kawin yang diajukan ke PA tersebut mencapai 350 perkara dan diputus sebanyak 324 perkara.

Kantor Urusan Agama Kecamatan Anreapi Kabupaten Polewali Mandar mengatakan bahwa terdapat 23 orang yang melalukan pernikahan dini pada tahun 2016 dan mengalami peningkatan pada tahun 2017 yaitu mencapai 37 (KAU, 2018)

Dalam melakukakan penelitian, peneliti tidak mungkin melakukan penelitian pada seluruh populasi yang diinginkan, melainkan dengan cara mengambil contoh (sampel), yang disatu sisi mewakili populasi induknya, dan dilain sisi mampu laksana ditinjau dari ketersedian waktu, tenaga, sarana, serta biaya. (Sudigdo Sastroasmoro,2009)

\section{Populasi}

$$
\text { Populasi dalam }
$$
penelitian adalah sejumlah besar subjek yang mempunyai karakteristik tertentu subyek dapat berupa manusia, hewan coba, data 
laboratorium, dan lain-lain, sedang karakter subyek ditentukan sesuai dengan ranah dan tujuan penelitian.

$$
\text { Populasi dalam }
$$

penelitian ini adalah siswi putri SMPN Anreapi yang berjumlah 65 orang

\section{Sampel}

Sampel adalah bagian dari populasi yang dipilih dengan cara tertentu hingga dianggap dapat mewakili populasinya.

Sampel yang
digunakan dalam
penelitian ini adalah total
populasi, yaitu siswi putri
SMPN Anreapi yang
berjumlah 65 orang

\section{Sampling}

Tehnik sampling adalah suatu proses seleksi sampel yang digunakan dalam penelitian dari populasi yang ada, sehingga jumlah sampel akan mewakili keseluruhan populasi yang ada (Alimul Hidayat, 2009)

Dalam penelitian ini menggunakan tehnik accidental. Accidental sampling adalah pengambilan sampel yang dilakukan sesaat. Sehinnga sampel yang diperoleh adalah sampel yang ada atau tersedia pada waktu itu (Suryono, 2011)

\section{HASIL PENELITIAN DAN PEMBAHASAN \\ Karakteristik Responden}

Umur

Tabel 4.1

Distribusi Frekuensi Responden Berdasarkan Umur

Di SMPN Anreapi Kec. Anreapi

Kab. Polewali Mandar

\begin{tabular}{|c|c|c|c|}
\hline No & Umur responden & Frekuensi & Presentase (\%) \\
\hline 1 & 14 & 32 & 49,24 \\
\hline 2 & 15 & 30 & 46,2 \\
\hline 3 & 16 & 3 & 4,6 \\
\hline \multicolumn{2}{|r|}{ Total } & 65 & 100 \\
\hline
\end{tabular}

Sumber : Data Primer 
Berdasarkan tabel 4.1 tentang umur responden, dimana hasil penelitian menunjukan bahwa dari 65 responden yang berusia 14 tahun sebanyak 32

Kelas responden atau $(49,24 \%)$, yang berusia 15 tahun sebanyak 30 responden atau $(46,2 \%)$ dan yang berusia 16 tahun sebanyak 3 responden atau $(4,6 \%)$

Tabel 4.2

Distribusi Frekuensi Responden Berdasarkan Kelas

Di SMPN Anreapi Kec. Anreapi

Kab. Polewali Mandar

\begin{tabular}{|c|c|c|c|}
\hline No & Kelas & Frekuensi & Presentase (\%) \\
\hline 1 & Kelas II & 43 & 66,2 \\
\hline 2 & Kelas III & 22 & 33,8 \\
\hline \multicolumn{2}{|r|}{ Total } & 65 & 100 \\
\hline
\end{tabular}

Sumber : Data Primer

Berdasarkan tabel 4.2 sebanyak 43 responden atau menunjukan bahwa distribusi (66,2\%) dan kelas III sebanyak 22 kelas dari 65 responden kelas II responden atau $(33,8 \%)$

\section{Pendidikan}

Tabel 4.3

Distribusi Frekuensi Responden Berdasarkan Pendidikan

Di SMPN Anreapi Kec. Anreapi

Kab. Polewali Mandar

\begin{tabular}{|c|c|c|c|}
\hline No & Kelas & Frekuensi & Presentase (\%) \\
\hline 1 & SMP & 65 & 100 \\
\hline \multicolumn{2}{|c|}{ Total } & 65 & 100 \\
\hline
\end{tabular}

Sumber : Data Primer 
Berdasarkan tabel 4.3 tentang pendidikan responden menunjukan bahwa distribusi pendidikan responden semuanya adalah SMP yaitu sebanyak 65 responden atau $100 \%$

\section{Variabel Yang Diteliti}

Gambaran Pengetahuan Remaja Tentang Pengertian Remaja

Tabel 4.4

Distribusi Frekuensi Tingkat Pengetahuan Remaja

Tentang Pengertian Remaja Di SMPN Anreapi

Kec. Anreapi Kab. Polewali Mandar

\begin{tabular}{|l|l|l|l|}
\hline No & Kategori & Frekuensi & Presentase (\%) \\
\hline 1 & Baik & 6 & 9,23 \\
\hline 2 & Cukup & 19 & 29,23 \\
\hline 3 & Kurang & 40 & 61,54 \\
\hline \multicolumn{2}{|l|}{ Total } & $\mathbf{6 5}$ & $\mathbf{1 0 0}$ \\
\hline
\end{tabular}

sumber : Data Primer

Berdasarkan tabel 4.4 responden atau $(9,23 \%)$, yang menunjukan bahwa pengetahuan memperoleh kriteria cukup sebanyak responden tentang pengertian remaja, 19 responden atau $(29,23 \%)$ dan dimana hasil penelitian menunjukan yang memperoleh kriteria kurang bahwa dari 65 responden yang sebanyak 40 responden atau $(61,54 \%$ memperoleh kriteria baik sebanyak 6

Gambaran Pengetahuan Remaja Tentang Penyebab Pernikahan Dini

Tabel 4.5

Distribusi Frekuensi Tingkat Pengetahuan Remaja Tentang Penyebab Pernikahan Dini Di SMPN Anreapi

Kec. Anreapi Kab. Polewali Mandar 


\begin{tabular}{|c|l|l|l|}
\hline No & \multicolumn{1}{|c|}{ Kategori } & \multicolumn{1}{|c|}{ frekuensi } & \multicolumn{1}{|c|}{ Presentase (\%) } \\
\hline 1 & Baik & 8 & 12,31 \\
\hline 2 & Cukup & 24 & 36,92 \\
\hline 3 & Kurang & 33 & 50,77 \\
\hline Total & $\mathbf{6 5}$ & $\mathbf{1 0 0}$ \\
\hline
\end{tabular}

Sumber : Data Primer

Berdasarkan tabel 4.5 baik sebanyak 8 responden atau menunjukan bahwa pengetahuan (12,31\%), yang memperoleh kriteria responden tentang penyebab cukup sebanyak 24 responden atau pernikahan dini , dimana hasil (36,92\%) dan yang memperoleh penelitian menunjukan bahwa dari $65 \quad$ kriteria kurang sebanyak 33 responden yang memperoleh kriteria responden atau $(50,77 \%)$

\section{Gambaran Pengetahuan Remaja Tentang Resiko Pernikahan Dini}

Tabel 4.6

Distribusi Frekuensi Tingkat Pengetahuan Remaja Tentang Resiko Pernikahan Dini Di SMPN Anreapi Kec. Anreapi Kab. Polewali Mandar

\begin{tabular}{|c|c|c|c|}
\hline No & Kategori & frekuensi & Presentase (\%) \\
\hline 1 & Baik & 26 & 40 \\
\hline 2 & Cukup & 20 & 30,77 \\
\hline 3 & Kurang & 19 & 29,23 \\
\hline \multicolumn{2}{|c|}{ Total } & 65 & 100 \\
\hline
\end{tabular}

Sumber : Data Primer

Berdasarkan tabel 4.6 menunjukan bahwa pengetahuan responden tentang resiko pernikahan dini, dimana hasil penelitian menunjukan bahwa dari 65 responden yang

memperoleh kriteria baik sebanyak 26 responden atau (40\%), yang memperoleh kriteria cukup sebanyak 20 responden atau $(30,77 \%)$ dan yang memperoleh kriteria 
Gambaran Pengetahuan Remaja Tentang Penanggulangan Pernikahan Dini

Tabel 4.7

Distribusi Frekuensi Tingkat Pengetahuan Remaja Tentang
Penanggulangan Pernikahan Dini Di SMPN Anreapi

Kec. Anreapi Kab. Polewali Mandar

\begin{tabular}{|c|l|l|l|}
\hline No & \multicolumn{1}{|c|}{ Kategori } & \multicolumn{1}{|c|}{ frekuensi } & \multicolumn{1}{|c|}{ Presentase (\%) } \\
\hline 1 & Baik & 2 & 3,1 \\
\hline 2 & Cukup & 14 & 21,54 \\
\hline 3 & Kurang & 49 & 75,38 \\
\hline Total & & $\mathbf{6 5}$ & $\mathbf{1 0 0}$ \\
\hline
\end{tabular}

Sumber : Data Primer

Berdasarkan tabel 4.7 baik sebanyak 2 responden atau menunjukan bahwa pengetahuan $(3,1 \%)$, yang memperoleh kriteria responden tentang penanggulangan cukup sebanyak 14 responden atau pernikahan dini, dimana hasil (21,54\%) dan yang memperoleh penelitian menunjukan bahwa dari $65 \quad$ kriteria kurang sebanyak 49 responden yang memperoleh kriteria responden atau $(75,38 \%)$

Gambaran Pengetahuan Remaja Putri Tentang Pernikahan Dini

Tabel 4.8

Distribusi Frekuensi Tingkat Pengetahuan Remaja Tentang Pernikahan Dini Di SMPN Anreapi Kec. Anreapi

Kab. Polewali Mandar

\begin{tabular}{|c|l|l|l|}
\hline No & \multicolumn{1}{|c|}{ Kategori } & \multicolumn{1}{|c|}{ frekuensi } & Presentase (\%) \\
\hline 1 & Baik & 4 & 6,2 \\
\hline 2 & Cukup & 46 & 70,77 \\
\hline 3 & Kurang & 15 & 23,1 \\
\hline \multicolumn{2}{|c|}{ Total } & $\mathbf{6 5}$ & $\mathbf{1 0 0}$ \\
\hline
\end{tabular}

Sumber : Data Primer 
Berdasarkan tabel 4.8 menunjukan bahwa pengetahuan responden tentang Pernikahan Dini, dimana hasil penelitian menunjukan bahwa dari 65 responden yang memperoleh kriteria baik

\section{Pembahasan}

\section{Tingkat Pengetahuan Remaja Tentang Pengertian Remaja}

Masa remaja merupaka masa peralihan dari masa kanak-kanak kemasa dewasa yang telah mencapai yang telah tercapai usia 10 sampai 20 tahun dengan terjadinya perubahan fisik, mental dan psikologi yang cepat dan berdampak pada berbagai aspek kehidupan selanjutnya.Menurut stanley Hall, seorang Bapak pelopor Psikologi Perkembangan Remaja, masa remaja dianggap sebagai masa "topan badai dan stres" (stromand stress), karena mereka telah memiliki keinginan untuk bebas menentukan nasib dari diri sendiri (Mansur, 2009).

Hasil penelitian tingkat pengetahuan responden tentang pengertian remaja berdasarkan tabel 4.4 menunjukan bahwa pengetahuan responden tentang pengertian remaja, sebanyak 4 responden atau $(6,2 \%)$, yang memperoleh kriteria cukup sebanyak 46 responden atau $(70,77 \%)$ dan yang memperoleh kriteria kurang sebanyak 15 responden atau $(23,1 \%)$

dimana hasil penelitian menunjukan bahwa dari 65 responden yang memperoleh kriteria baik sebanyak 6 responden atau $(9,23 \%)$, yang memperoleh kriteria cukup sebanyak 19 responden atau $(29,23 \%)$ dan yang memperoleh kriteria kurang sebanyak 40 responden atau $(61,54 \%)$.

Berdasarkan penelitian yang telah dilakukan dapat ditarik kesimpulan bahwa pengetahuan responden tentang pengertian remaja di SMPN Anreapi Kecamatan Anreapi Kabupaten Polewali Mandar Tahun 2018 berada pada kategori cukup.

\section{Tingkat Pengetahuan Remaja Tentang Penyebab Pernikahan Dini}

$\begin{array}{lrr} & \text { Pernikahan } & \text { adalah } \\ \text { peristiwa ketika } & \text { sepasang } \\ \text { mempelai } & \text { dipertemukan } \\ \text { secara formal di } & \text { hadapkan } \\ \text { penghulu atau kepala } & \text { agama } \\ \text { tertentu, para raksi,dan } & \text { salu } \\ \text { sejumlah hadirin } & \text { untuk } \\ \text { kemudian } & \text { disahkan } & \text { secara }\end{array}$


resmi sebagai suami istri melalui upacara (Irianti dkk, 2011)

Di Indonesia pasal 7 Undang - Undang no 1 tentang perkawinan tahun 1974 menetapkan bahwa perkawinan di izinkan bila pria berusia 19 tahun dan wanita berusia 16 tahun, tetapi pada gerakkan pendewasaan Usia Perkawinan (PUP) untuk meningkatkan rata-rata usia kawin pertama (UKP) wanita secara ideal, perempuan 20 tahun dan laki-laki 25 tahun. Banyaknya perkawinan di usia muda itu sangat berpengaruh pada kesehatan reproduksi, jumlah kematian ibu melahirkan, tingkat kesejahteraan ekonomi keluarga (Sibagariang dkk, 2010).

Ada beberapa faktor penyebab terjadinya perkawinan dini pada kalangan remaja yaitu sebab dari anak dan luar anak baik itu dari orang tua, adat istiadat, ekonomi maupun pendidikan.

Hasil penelitian
tingkat pengetahuan
responden tentang penyebab
pernikahan dini berdasarkan
tabel 4.5 menunjukan bahwa
pengetahuan responden

tentang penyebab pernikahan dini , dimana hasil penelitian menunjukan bahwa dari 65 responden yang memperoleh kriteria baik sebanyak 8 responden atau (12,31\%), yang memperoleh kriteria cukup sebanyak 24 responden atau $(36,92 \%)$ dan yang memperoleh kriteria kurang sebanyak 33 responden atau $(50,77 \%)$

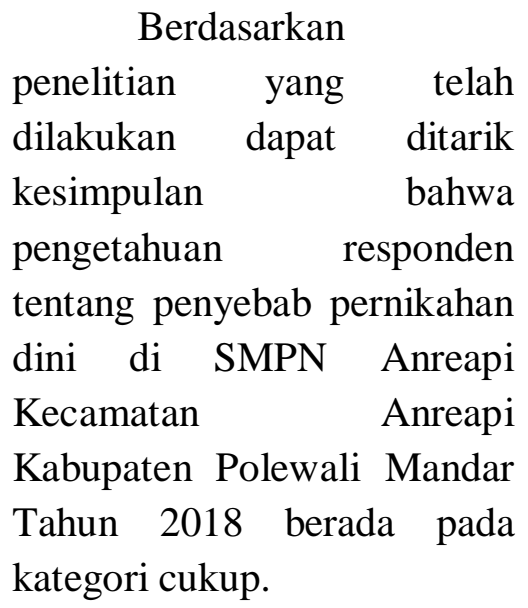

\section{Tingkat Pengetahuan Remaja} Tentang Resiko Pernikahan Dini

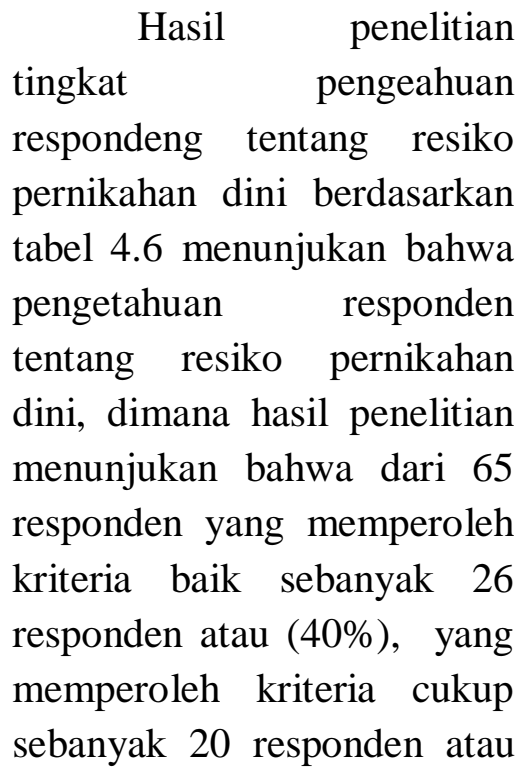


$(30,77 \%) \quad$ dan yang memperoleh kriteria kurang sebanyak 19 responden atau $(29,23 \%)$.

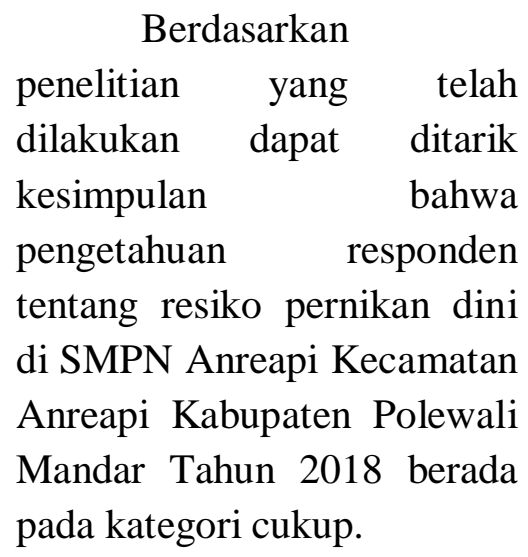

\section{Tingkat Pengetahuan Remaja Tentang Penanggulanagan \\ Pernikahan Dini}

Perencanaan keluarga

berencana atau mejarakan

kehamilan dianggap sangat penting pada remaja yang melakukan pernikahan dini karena belum siap dipandang dari sisi kesehatan maupun perkembangan emosional untuk menghadapi kehidupan berkeluarga.

$\begin{array}{lr}\text { Hasil } & \begin{array}{r}\text { penelitian } \\ \text { pengetahuan } \\ \text { tingkat } \\ \text { respontang } \\ \text { penanggulangan }\end{array} \\ \begin{array}{lr}\text { dini bernikahan } \\ \text { menunjukan }\end{array} \\ \text { pengetahuan } & \text { bahwa } \\ \text { tentang penanggulanagan } \\ \text { pernikahan dini, dimana hasil } \\ \text { penelitian menunjukan bahwa } \\ \text { dari } 65 \text { responden yang }\end{array}$

memperoleh kriteria baik sebanyak 2 responden atau $(3,1 \%)$, yang memperoleh kriteria cukup sebanyak 14 responden atau $(21,54 \%)$ dan yang memperoleh kriteria kurang sebanyak 49 responden atau $(75,38 \%)$. Berdasarkan

penelitian yang telah dilakukan dapat ditarik kesimpulan bahwa pengetahuan responden tentang penanggulanagan pernikahan dini di SMPN Anreapi Kecamatan Anreapi Kabupaten Polewali Mandar Tahun 2018 berada pada kategori cukup.

\section{Tingkat Pengetahuan Remaja} Tentang Pernikahan Dini Masa remaja merupakan masa peralihan dari masa kanak-kanak kemasa dewasa yang telah mencapai yang telah tercapai usia 10 sampai 20 tahun dengan terjadinya perubahan fisik, mental dan psikologi yang cepat dan berdampak pada berbagai aspek kehidupan selanjutnya. Menurut stanley Hall, seorang Bapak pelopor Psikologi Perkembangan Remaja, masa remaja dianggap sebagai masa "topan badai dan stres" (stromand stress), karena mereka telah memiliki 


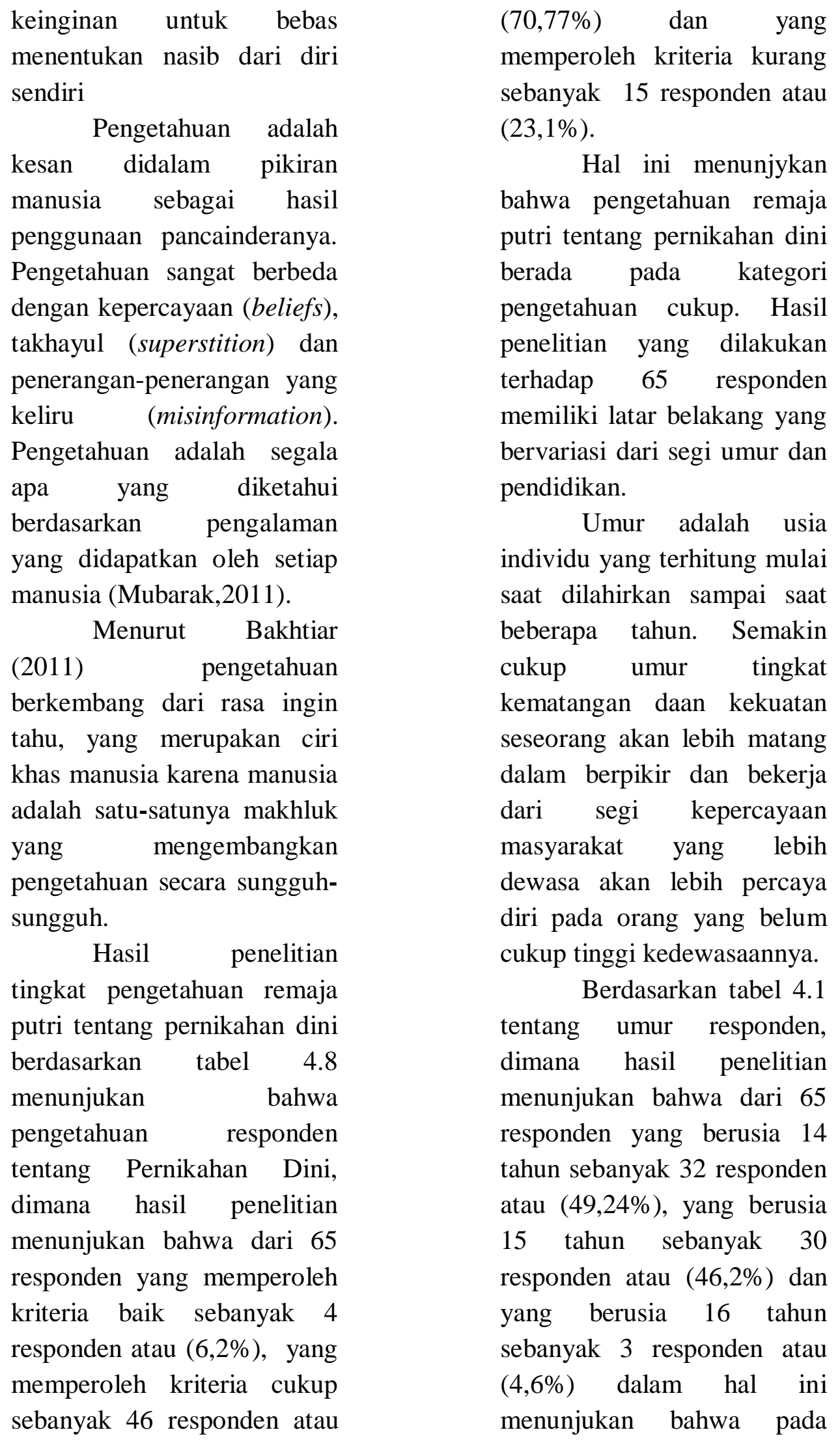


$\begin{array}{lll}\text { kelompok } & \text { umur } & \text { tersebut } \\ \text { responden } & \text { tidak } & \begin{array}{r}\text { terdapat } \\ \text { tentang }\end{array}\end{array}$ kepemilikan pengetahuan lebih disebabkan adanya perbedaan tingkat motivasi dari remaja itu sendiri.

Pendidikan adalah usaha yang sadar untuk mengembangkan kepribadian dan kemampuan didalam dan diluar sekolah dan berlansung seumur hidup.

Berdasarkan tabel 4.3 tentang pendidikan responden menunjukan bahwa distribusi pendidikan responden semuanya adalah SMP yaitu sebanyak 65 responden atau $100 \%$. Hal diatas tersebut menandakan bahwa proses kognitif yang mengawli terjadinya proes tahu atau pengetahuan seseorang dipengaruhi oleh faktor internal (pribadi) dan faktor eksternal (lingkungan) faktor internal seseorang meliputi pengalaman, keinginan, motivasi dan tujuan. Sedangkan faktor eksternal meliputi lingkungan hidup, fisik dan sosial budaya.

Berdasarkan hasil penelitian dapat dilihat hasil penelitian semua responden berpendidikan SMP dimana tingkat menengah pertama akan sulit menerima pesan karena sebelumnya tidak pernah mendapatkan informasi tentang hal tersebut sehingga kurang mengerti dan memahami tentang resiko pernikahan dini dalam kehamilan.

Hasil penelitian tingkat pengetahuan remaja putri tentang pernikahan dini berdasarkan tabel 4.8 menunjukan bahwa pengetahuan responden tentang Pernikahan Dini, dimana hasil penelitian menunjukan bahwa dari 65 responden yang memperoleh kriteria baik sebanyak 4 responden atau $(6,2 \%)$, yang memperoleh kriteria cukup sebanyak 46 responden atau $(70,77 \%)$ dan yang memperoleh kriteria kurang sebanyak 15 responden atau $(23,1 \%)$.

Jadi kesimpulan pada penelitian tentang tingkat pengetahuan remaja putri tentang pernikahan dini di SMPN Anreapi Kecamatan Anreapi Kabupaten Polewali Mandar Tahun 2018 berada pada kategori cukup.

\section{PENUTUP}

\section{Simpulan}

Berdasarkan hasil penelitian dan analisa data dapat disimpulkan bahwa :

Gambaran pengetahuan responden tentang pengertian 
remaja menunjukan bahwa dari 65 responden yang memperoleh kriteria baik sebanyak 6 responden atau (9,23\%), yang memperoleh kriteria cukup sebanyak 19 responden atau $(29,23 \%)$ dan yang memperoleh kriteria kurang sebanyak 40 responden atau $(61,54 \%)$

Gambaran pengetahuan responden tentang penyebab pernikahan dini menunjukan bahwa dari 65 responden yang memperoleh kriteria baik sebanyak 8 responden atau $(12,31 \%)$, yang memperoleh kriteria cukup sebanyak 24 responden atau $(36,92 \%)$ dan yang memperoleh kriteria kurang sebanyak 33 responden atau $(50,77 \%)$

Gambaran pengetahuan responden tentang resiko pernikahan dini menunjukan bahwa dari 65 responden yang memperoleh kriteria baik sebanyak 26 responden atau (40\%), yang memperoleh kriteria cukup sebanyak 20 responden atau $(30,77 \%)$ dan yang memperoleh kriteria kurang sebanyak 19 responden atau $(29,23 \%)$

Gambaran pengetahuan responden tentang penanggulanagan pernikahan dini, menunjukan bahwa dari 65 responden yang memperoleh kriteria baik sebanyak 2 responden atau $(3,1 \%)$, yang memperoleh kriteria cukup sebanyak 14 responden atau $(21,54 \%)$ dan yang memperoleh kriteria kurang sebanyak 49 responden atau $(75,38 \%)$

Secara keseluruhan gambaran pengetahuan remaja putri tentang Pernikahan Dini, dimana hasil penelitian menunjukan bahwa dari 65 responden yang memperoleh kriteria baik sebanyak 4 responden atau $(6,2 \%)$, yang memperoleh kriteria cukup sebanyak 46 responden atau $(70,77 \%)$ dan yang memperoleh kriteria kurang sebanyak 15 responden atau $(23,1 \%)$. Jadi kesimpulan pada penelitian tentang tingkat pengetahuan remaja putri tentang pernikahan dini di SMPN Anreapi Kecamatan Anreapi Kabupaten Polewali Mandar Tahun 2018 berada pada kategori cukup.

\section{Saran}

Berdasarkan hasil penelitian"Gambaran

Pengetahuan Remaja Putri Tentang Pernikahan Dini Di SMPN Anreapi Kec. Anreapi Kab. Polewali Mandar" maka penulis menyarankan :

\section{Bagi Institusi Pendidikan}

Untuk menambah pengetahuan yang berkaitan dengan pernikahan dini. 


\section{Bagi Lokasi penelitian}

Untuk memberikan penjelasan dan pendidikan kesehatan tentang pernikahan dini yang dapat menimbulkan dampak social, psikolog maupun kesehatan remaja.

\section{DAFTAR PUSTAKA}

Adjie S. 2009. Kesehatan Reproduksi Remaja dalam Aspek Sosial. http://www.idai.or.id.Diakses : 17 Juli 2012.

Anwar, S. D. 2016. Kebijakan dan program pemerintah dalam mengatasi perkawinan anak. From http://kajiangender.pps.ui.ac.id

Desiyanti, I. W. 2015. Faktor-faktor yang berhubungan terhadap pernikahan dini pada pasangan usia subur. JIKMU. 5(2), 270-280.

Dharmayanti M. 2009.Kesehatan Reproduksi Remaja. http://www.idai.or.id.Diakses : 17 Juli 2012

Irianti I, Herlina N. 2011. Buku Ajar Psikologi Untuk

MahasiswaKebidanan.Jakarta :EGC

Kusmiran E. 2011. Kesehatan Reproduksi Remaja dan Wanita. Jakarta :SalembaMedika
Kusmiyati Y, dkk. 2009. Perawatan Ibu Hamil(Asuhan Ibu Hamil). Yogyakarta : Fitramaya

Mubarak, I W. 2012. Promosi Kesehatan Untuk Kebidanan. Jakarta :Salemba Medika

Manusur H. 2009. Psikologi Ibu dan Anak Untuk Kebidanan. Jakarta :SalembaMedika

Notoatmodjo S. 2010. Metodologi Penelitian Kesehatan. Jakarta : Rineka Cipta

Pieter J H, Janiwarti,B. 2010. Pengantar Psikologi Untuk Kebidanan. Jakarta : Rawamangun

Saryono. 2011. Metodologi Penelitian Kesehatan Penuntun PraktisBagi Pemula. Jogjakarta :Mitra Cendikia Press

Sibagariang E E, dkk. 2010. Kesehatan Reproduksi Wanita. Jakarta :Trans Info Menika Suriasumantri. 2007. Filsafat Ilmu, Sebuah Pengantar Populer. Jakarta. : PustakaSinar Harapan

Rahma F J. 2012. Resiko Pada Remaja Akibat Pernikahan Dini.

http://modalyakin.blogspot.co m.Diakses : 29 Mei 2012.

Rahayu, 2012. Jurnal Penelitian, Gambaran Pengetahuan remaja tentang

PUP.http://dunuailmu.wordpress.co m, diakses : 7 juli 2016. 